\title{
Almanac 2013: Acute coronary syndromes
}

The national society journals present selected research that has driven recent advances in clinical cardiology.

The article was first published in Heart 2013;99:20 1488-1493 Published Online First: 14 August 2013 doi:10.1136/heartjnl-2013-304649, and is republished with permission.

\section{Pascal Meier ${ }^{1,2}$, Alexandra J Lansky ${ }^{1}$, Andreas Baumbach ${ }^{3}$}

${ }^{1}$ Division of Cardiology, Yale Medical School, New Haven, Connecticut, USA, ${ }^{2}$ Yale-UCL Cardiovascular Research Programme, The Heart Hospital, University College London Hospitals UCLH, London, UK, ${ }^{3}$ Division of Cardiology, Bristol Heart Institute, Bristol, UK (ACS) and can manifest as unstable angina, non-ST segment elevation infarction (NSTE-ACS), and ST elevation myocardial infarction (STEMI), but can also manifest as sudden cardiac arrest due to ischaemia induced tachyarrhythmias. ACS mortality has decreased significantly over the last few years, especially from the more extreme manifestations of ACS, STEMI, and cardiac arrest. This trend is likely to continue based on recent therapeutic progress which includes novel antiplatelet agents such as prasugrel, ticagrelor, and cangrelor.

\section{Introduction}

$\mathrm{n}$ the USA every year nearly 1.2 million patients are hospitalised for acute coronary syndrome (ACS). ${ }^{1}$ However, the proportion of ACS with ST elevation myocardial infarction (STEMI) appears to be declining. ${ }^{23}$ We can only speculate upon the reasons: potential explanations include the reduction in smoking, the age structure of the population (STEMI is more common in middle age while non-ST segment elevation (NSTE-ACS) occurs more in the elderly), and broader use of statin therapy. Over the last few years there has been a significant improvement in outcomes after STEMI in regard to mortality, cardiogenic shock, and heart failure. ${ }^{1}$ Similar trends have been seen for other manifestations of ACS, such as sudden cardiac arrest (SCA). ${ }^{45}$ Astonishingly, the clinical outcomes for NSTE-ACS now appear to be worse than for STEMI. However, such figures are misleading, and short term (in-hospital) outcome is still better for NSTE-ACS than for STEMI, while the longer term mortality rate is higher for NSTE-ACS, but this is probably influenced by the different age and risk structure of the STEMI and NSTE-ACS populations: NSTE-ACS patients are generally older and often have multivessel (MV) coronary artery disease (CAD).

\section{ST Elevation Myocardial Infarction}

A major reason for the improved outcomes for STEMI over the last decades has been the increasing availability of primary percutaneous coronary intervention ( $\mathrm{PCl}$ ) services, which all try to continuously improve their performance ('door-toballoon time'). Initiatives include telemetric transmission of ECGs from the ambulance services, and training of ambulance staff in ECG interpretation. More important than door-to-balloon time is of course the overall 'symptom onset to balloon time'. Patients have become much better informed about symptoms of 'heart attacks', and many ambulance services transfer patients with a suspected STEMI directly to a primary $\mathrm{PCl}$ service rather than going to the nearest hospital.

\section{Primary Percutaneous Coronary Intervention}

Not only has the rate of primary $\mathrm{PCl}$ increased over the years, but progress in device technologies and adjunctive pharmacology has also improved the procedural success rate-for example, the availability of stents and second generation drug eluting stents, thrombus aspiration devices, and safer and more effective periprocedural anticoagulation/antiplatelet treatments. Thrombus aspiration has been shown to improve outcomes in smaller randomised trials and is currently recommended by European and American $\mathrm{PCl}$ guidelines. However, its effect should probably not be overrated. A recent large scale randomised trial in 452 patients, INFUSE-AMI (Intracoronary Abciximab and Aspiration Thrombectomy in Patients with Large Anterior Myocardial Infarction) did not demonstrate an effect of manual thrombus aspiration on infarct size when used in conjunction with bivalir-

udin (and intracoronary abciximab). ${ }^{67}$ Intravenous glycoprotein (Gp) Ilb/IIla inhibitors have an immediate and potent platelet inhibitory effect and certainly improve thrombus resolution; they may reduce infarct size ${ }^{6}$ 
Table 1. Bleeding avoidance strategies ${ }^{9}$

\begin{tabular}{|l|l|}
\hline Strategy & Comments \\
\hline Radial instead of femoral access & Reduces access site bleeding risk (and potentially also mortality in high risk groups) \\
\hline Bivalirudin & $\begin{array}{l}\text { Bivalirudin superior to heparin and glycoprotein Ilb/IIla inhibitors, reduces bleeding } \\
\text { (and reduces mortality in STEMI patients) }\end{array}$ \\
\hline $\begin{array}{l}\text { Fluoroscopy guided puncture for } \\
\text { femoral access }\end{array}$ & $\begin{array}{l}\text { High (or low) puncture to be avoided. The femoral head has a consistent relationship } \\
\text { with the common femoral artery, and localisation using fluoroscopy is a useful land- } \\
\text { mark. However, randomised studies failed to show a clinical benefit but were } \\
\text { underpowered }\end{array}$ \\
\hline $\begin{array}{l}\text { Ultrasound guided puncture for } \\
\text { femoral access }\end{array}$ & Fewer vascular complications with this approach in randomised trials \\
\hline Vascular closure devices & $\begin{array}{l}\text { Controversial study results. Increasing evidence pointing towards a positive effect of } \\
\text { vascular closure devices, especially if used with bivalirudin }\end{array}$ \\
\hline $\begin{array}{l}\text { Individualised bleeding risk } \\
\text { assessment }\end{array}$ & $\begin{array}{l}\text { Individualised risk assessment and adjustment of clinical practice using risk models, } \\
\text { for example, NCDR CathPCI bleeding risk model (bivalirudin, radial access, etc) }\end{array}$ \\
\hline
\end{tabular}

NCDR, National Cardiovascular Database Registry; PCl, percutaneous coronary interventions; STEMI, ST elevation myocardial infarction.

while their effect on clinical outcomes is somewhat more debatable. Bivalirudin, a direct thrombin inhibitor, which has anticoagulant and probably also antiplatelet effects (via suppression of thrombin dependent platelet activation $\left.^{8}\right)$, can be used as an alternative to heparin and Gp Ilb/Illa inhibitors, and has shown reduced bleeding and even reduced mortality in the HORIZON-AMI trial (Heparin plus a glycoprotein IIb/IIla Inhibitor versus Bivalirudin Monotherapy and Paclitaxel-Eluting Stents versus Bare-Metal Stents in Acute Myocardial Infarction). ${ }^{6}$ Bleeding reduction has become a key aim in primary $\mathrm{PCl}$ because of the well documented (but less well understood) association with increased mortality (table 1).

\section{Transradial versus transfemoral access}

Another rather elegant option used increasingly, which may reduce bleeding, involves the transradial approach instead of the traditional transfemoral access. ${ }^{9} \mathrm{An}$ increasing wealth of data indicate that this reduces bleeding in general; some data even suggest that it reduces mortality when used for primary $\mathrm{PCl}$, but the latter effect is debatable. ${ }^{1011} \mathrm{~A}$ recent meta-analysis of nine studies involving 2977 patients with STEMI demonstrated an impressive nearly $50 \%$ reduction in mortality for the transradial approach (OR $0.53,95 \% \mathrm{Cl} 0.33$ to 0.84 ; $\mathrm{p}=0.008) .{ }^{10}$ While the authors concluded that the transradial approach should be preferred in STEMI patients, an accompanying editorial highlighted some limitations of these data. ${ }^{11}$ Some data indicate a negative impact of transradial $\mathrm{PCl}$. Baklanov et $\mathrm{al}^{12}$ showed a longer median door-to-balloon time with transradial $\mathrm{PCl}$. Another retrospective comparison by Cafri et al, ${ }^{13}$ however, showed similar door-to-balloon time irrespective of the access route. Even in elderly people, where there is more advanced atherosclerosis, the radial access does not seem to delay reperfusion as it does not lead to any increase in the door-to-balloon time. ${ }^{14}$ There have also been concerns that transradial access may increase the risk of neurological complications compared to transfemoral access. However, in a retrospective analysis of the British Cardiovascular Intervention Society database conducted between January 2006 and December 2010,
Ratib et $\mathrm{al}^{15}$ have shown that there is no significant association between the use of radial access and the occurrence of neurological complications.

Overall, transradial $\mathrm{PCl}$ is certainly a promising technique when used by experienced operators. However, despite its benefits, its use is highly variable across countries. In France and Japan it is the predominant access route. ${ }^{11}$ In the UK, its use increased nearly fourfold from $17.2 \%$ in 2006 to $57 \%$ in $2011 .{ }^{16}$ The USA has the lowest rate of radial access adoption

for $\mathrm{PCl}$ worldwide (only one in six PCls).${ }^{17}$ Even here, there has been an increase in use of radial access. In the first quarter of $2007,1.2 \%$ of $\mathrm{PCl}$ s were by the transradial approach; this increased to $16.1 \%$ in the third quarter of 2012. There is little doubt that the increasing use of transradial $\mathrm{PCl}$ has led to a reduction in access site complications. 12161718

While some data indicate that the transradial route may reduce mortality in STEMI patients, this has not been demonstrated in NSTE-ACS. In the RIVAL (Radial vs Femoral Access for Coronary Intervention) trial, currently the largest randomised trial on this topic, there was no difference in major clinical outcomes in NSTEACS patients. ${ }^{19}$ In a cohort of high risk NSTE-ACS patients enrolled in the EARLY-ACS trial (Early Glycoprotein IIb/ Illa Inhibition in non-ST-Segment Elevation

Acute Coronary Syndrome), there were no significant differences in either bleeding or ischaemic outcomes whether radial or femoral access was used. ${ }^{20}$

A recent consensus statement by the European Society of Cardiology (ESC) states that a default radial approach is feasible in routine practice in both stable and unstable patients. ${ }^{21}$ The ESC recommends performing transradial $\mathrm{PCl}$ in STEMI patients only after the operator has become familiar with this approach in stable patients and in diagnostic procedures.

\section{Culprit lesion $\mathrm{PCl}$}

Culprit lesion only treatment versus a 'complete revascularisation' approach remains the subject of some debate. One could argue either way: a complete revascularisation strategy may improve overall myocardial 
perfusion in the critical initial phase; but on the other hand, we know that major adverse complications are increased during acute $\mathrm{PCl}$, and this also may have an impact on the outcome following treatment of nonacute, nonculprit lesions. A randomised study of 214 patients showed that angioplasty of the culprit vessel only was associated with higher rates of adverse events (50.0\%) during a mean follow up of

2.5 years than $\mathrm{MV} \mathrm{PCl}$, regardless of simultaneous complete revascularisation (23.1\%) or a staged complete revascularisation (20.0\%). ${ }^{22} \mathrm{~A}$ recent report of the Ibaraki Cardiovascular Assessment Study registry of Japan showed significantly higher mortality with $\mathrm{PCl}$ of a non-culprit lesion in the same setting as the culprit lesion than with $\mathrm{PCl}$ of only the culprit lesion. ${ }^{23}$ In contrast, results based of the American College of Cardiology National Cardiovascular Database Registry (NCDR-CathPCI) showed similar morbidity and mortality rates with either single vessel or $\mathrm{MV} \mathrm{PCl}{ }^{24}$ While these data were conflicting, most studies were nonrandomised and need to be interpreted with caution. A large meta-analysis of 18 randomised controlled trials (RCTs), including the above mentioned RCT, involved 40 280 patients and showed that staged $\mathrm{PCl}$ was associated with lower short and long term mortality compared to culprit vessel $\mathrm{PCl}$ and $\mathrm{MV} \mathrm{PCl} .{ }^{25}$ Therefore, current guidelines discourage the performance of multivessel PCI for STEMI and suggest that nonculprit lesions should be staged. ${ }^{2627}$ However, if STEMI patients present in cardiogenic shock or after an SCA, they should be considered for complete revascularisation in one sitting.

\section{The time effect}

The current ESC guidelines recommend that STEMI patients should be immediately transported within $2 \mathrm{~h}$ of onset of symptoms to a $\mathrm{PCl}$-capable centre without delay. ${ }^{28}$ In clinical practice, it is extremely difficult to achieve this goal of symptom onset-to-balloon time. ${ }^{29}$ System delays have been shown to be associated with mortality at a median follow-up of 3.4 years in STEMI patients treated with primary $\mathrm{PCl}^{30}$ In a more recent study, shorter symptom onset-to-balloon time predicted lower mortality in the long term. ${ }^{31} \mathrm{~A}$ longer treatment delay was seen in females, patients living in a rural area $>22 \mathrm{~km}$ from hospital, and when patients were admitted to the emergency department of the hospital instead of direct emergency medical services (EMS) transportation. Researchers suggest that a more generalised use of ambulance/EMS would reduce treatment delays and associated mortality.

\section{Optimal duration of monitoring/ hospital stay}

The duration of hospital stay has decreased dramatically over the years, which has a major impact on health care expenditure and on patient quality of life. Current practice is widely variable across countries and centres, but it is unclear whether early hospital discharges are safe. ${ }^{32}$ It is very reassuring that, despite the continuous reduction in hospital stay, outcomes have significantly improved (figure 1).

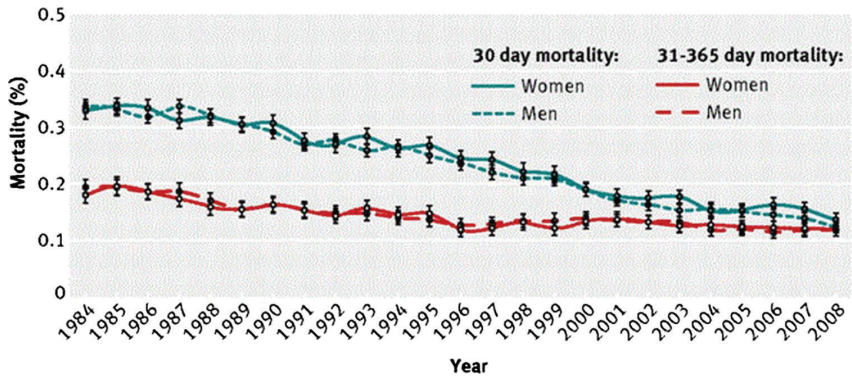

Figure 1. Change in short and intermediate term mortality after ST elevation myocardial infarction. Standardised 30 day and 31-365 day mortality after first hospitalisation for myocardial infarction among men and women between 1984 and 2008 in Denmark. ${ }^{33}$ Reprinted with permission from BMJ Publishing Group.

Two new studies have demonstrated that discharging low risk STEMI patients within 2 days following primary $\mathrm{PCl}$ is safe and feasible. ${ }^{34}{ }^{35}$ Over $40 \%$ of the STEMI patients in one of the studies met early discharge criteria. ${ }^{34} \mathrm{An}$ early discharge could lower healthcare costs considerably.

Based on the literature, we propose the following criteria to define low risk patients for early discharge:

1. Age $<70$ years

2. Short pain to reperfusion interval $(<4 \mathrm{~h})$

3. Uncomplicated primary $\mathrm{PCl}$ with good result (TIMI (Thrombolysis in Myocardial Infarction) 3 flow and prompt complete ST elevation resolution)

4. Left ventricular ejection fraction $>45 \%$ without symptoms of heart failure

5. No significant arrhythmias during the first $24 \mathrm{~h}$

6. Socially supported, collaborative/compliant patient.

\section{Non-ST Elevation ACS}

\section{Risk prediction}

There is a great need for proper risk prediction in ACS patients for clinical decision making, especially with regard to coronary angiography. There are several risk prediction models in use. The Global Registry of Acute Coronary Events (GRACE) is among the most commonly used scores. Recently, a mini-GRACE (MG) risk score has been developed which excludes creatinine and Killip class from the original eight-factor GRACE risk model. The adjusted mini-GRACE (AMG) risk score includes 'prescription of a loop diuretic during admission' in place of Killip class and creatinine concentration. Both risk scores showed good accuracy in the Myocardial Ischaemia National Audit Project (MINAP), with the AMG risk score performing somewhat better than the MG risk score. ${ }^{36}$

Laboratory markers may further help with this risk stratification. The maximal troponin value in patients presenting with NSTE-ACS has been shown to be an independent predictor of in-hospital morbidity and mortality. ${ }^{37}$ Other predictive markers include interleukin 10, myeloperoxidase, and placental growth factor. ${ }^{38}$ 


\section{Role and timing of $\mathrm{PCl}$ in NSTE-ACS}

For intermediate to high risk patients, there is strong evidence supporting routine angiography rather than conservative management. However, the optimal time for coronary angiography is not clear. Though an early invasive approach seems favourable, studies testing the timing effect used varying time points for 'early' and 'delayed' angiography. In very high risk patients such as those with refractory angina, severe heart failure, life threatening ventricular arrhythmias or haemodynamic instability or an evolving myocardial infarction (MI), an urgent invasive approach is indicated. For patients not belonging to this high risk category, the optimal timing is not clear. There is no clear benefit with regard to 'hard' clinical end points for an early invasive strategy within $24 \mathrm{~h}$, but an increasing number of centres undertake an early invasive strategy within $24 \mathrm{~h}$ for intermediate to high risk patients. Such an approach is probably reasonable, as an earlier approach certainly helps to reduce hospital stay. Factors such as diabetes, renal function, left ventricular function, recurrent symptoms, and previous revascularisation should be considered along with the TIMI or GRACE score.

\section{Intravascular imaging}

Intravascular imaging guided $\mathrm{PCl}$ is a concept that evolved when devices such as intravascular ultrasound (IVUS) and more recently optical coherence tomography (OCT) became available. There are two different modes of use, either for the pre- $\mathrm{PCl}$ assessment in order to better understand the coronary plaque (stable or unstable plaque, diameter and length, thrombus burden, etc), or for post-PCl assessment of stent expansion and apposition. The advantages are obvious; in contrast to angiography as an eyeballing tool, which allows measurement of luminal diameters in a few orthogonal views, coronary IVUS provides a tomographic view. Furthermore, the resolution is much better than for angiography.

The first concept, pre- $\mathrm{PCl}$ assessment of lesions has been tested in the multicentre PROSPECT (Providing Regional Observations to Study Predictors of Events in the Coronary Tree) study. ${ }^{39}$ This study showed that IVUS can be used to define characteristics of vulnerable plaques. The highest risk phenotypes associated with non-culprit major adverse cardiac events (MACE) included thin-cap fibroatheromas, plaque burden $>70 \%$, and minimal lumen area $<4.0 \mathrm{~mm}$. However, these data are not sufficient to advocate using IVUS derived plaque characteristics to decide whether a lesion needs to be treated. ${ }^{40}$

While IVUS is based on ultrasound, OCT is based on light, which has a much shorter wavelength, and therefore achieves 10-fold better spatial resolution compared to IVUS. ${ }^{41}$ This allows better definition of the thin fibrous caps and the circumferential extent of the necrotic cores. It helps detect other microstructural features such as cholesterol crystals, thrombus, calcium deposits, fibrous plaques, and lipid-rich plaques. ${ }^{42}$ OCT can visualise features not seen by IVUS such as intimal flaps and defects in the intima, disruptions in the media, and stent strut apposition.
A Japanese study that analysed the culprit lesion in AMI patients found that the incidence of plaque rupture observed by OCT was significantly higher than that observed by both angioscopy and IVUS..$^{43}$ OCT was also superior in detecting fibrous cap erosion and thin cap fibroatheroma, and OCT could also estimate the fibrous cap thickness. However, the depth of imaging penetration is limited to only a few millimetres with this new technique. ${ }^{44}$ So, it is unable to image the adventitia and assess the plaque burden. Therefore, Alfonso et $\mathrm{al}^{45}$ had the idea of a combined use of OCT and IVUS in patients with stent thrombosis. Since image length was shorter with OCT, they suggested overlapping OCT runs to circumvent the problem. The challenge of OCT is that it requires a field clear of blood for imaging.

Because OCT has superior resolution to IVUS, it clearly recognises stent struts on heavily calcified areas which are difficult to identify with IVUS. Post-intervention OCT also produces a sharper image of the neointimal-thrombus boundary and provides a reliable diagnosis of in-stent restenosis or neoatherosclerosis. In current practice, OCT and IVUS seem to complement each other with their respective advantages and disadvantages. However, we have to be aware that data on clinical outcomes are limited and that these techniques add to procedural costs.

\section{Antiplatelet therapy}

Aspirin is still the basis of every antiplatelet therapy. However, dual antiplatelet therapy of aspirin and a $\mathrm{P} 2 \mathrm{Y} 12$ receptor blocker is clearly more effective and clopidogrel is the most commonly used agent for this purpose at the moment. However, the problems with this treatment are the rather long delay until maximal platelet inhibition is reached and the high rate of poor responders. ${ }^{46}$ One approach that has been tested repeatedly is triple antiplatelet therapy using cilostazol. Even though results of this approach have indicated some benefit, it is rarely used. ${ }^{478}$ One reason for this is probably the development of newer generation P2Y12 receptor blockers such as prasugrel, ticagrelor, and cangrelor. They block the binding of ADP to the platelet receptor P2Y12, thereby inhibiting platelet aggregation. Naturally, we would expect that stronger antiplatelet inhibition comes with an increased bleeding risk. Many patients therefore receive proton pump inhibitors (PPI). However, the data do not completely following this logic.

Prasugrel: The TRITON-TIMI 38 trial was a head-to-head comparison between aspirin and prasugrel versus aspirin plus clopidogrel in 13608 moderate to high risk ACS patients undergoing $\mathrm{PCl}$. In most cases, the study drug was given after coronary angiography. At 15 months follow-up, MACE (cardiovascular death, non-fatal MI, or non-fatal stroke) was reduced with prasugrel $(9.9 \%$ vs $12.1 \%$; HR 0.81, $95 \% \mathrm{Cl}$

0.73 to 0.90 ) This composite end point was mainly driven by a reduction in non-fatal MI. Major bleeding was somewhat increased with prasugrel ( $2.4 \%$ vs $1.8 \%$; HR $1.32,95 \% \mathrm{Cl} 1.3$ to 1.68$)$. Bleeding was mainly increased in those with a history of stroke or transient ischaemic attack, age $\geq 75$ years or a bodyweight $\leq 60 \mathrm{~kg}$. The TRILOGY ACS trial tested prasugrel versus clopidogrel 
with NSTE-ACS not undergoing PCI. There was no statistically significant difference in MACE rate $(13.9 \%$ vs $16.0 \%$; HR $0.91,95 \% \mathrm{Cl} 0.79$ to 1.05 ).

Ticagrelor: In contrast to clopidogrel and prasugrel, ticagrelor binds reversibly to the $\mathrm{P} 2 \mathrm{Y} 12$ platelet receptor. This agent was tested in the PLATO trial (18 624 patients) in patients with ACS, and also those who did not undergo $\mathrm{PCl}$ but had medical therapy. Treatment was started early, at a median of $5 \mathrm{~h}$ after hospital admission. This study showed a reduced risk for MACE (defined as cardiovascular death, $\mathrm{MI}$, or stroke) in the ticagrelor arm ( $9.8 \%$ vs $11.7 \%, \mathrm{HR} 0.84,95 \% \mathrm{Cl} 0.77$ to 0.92 ), and there was also a reduced risk for cardiovascular mortality as a single end point. Overall, there was no significant difference in the rates of major bleeding between the ticagrelor and clopidogrel groups (11.6\% vs $11.2 \%$, respectively). However, there was a higher risk of non-coronary artery bypass surgery related major bleeding (4.5\% vs 3.8\%).

Cangrelor: In contrast to these drugs, cangrelor is administered intravenously. It has been tested against placebo and against clopidogrel. The CHAMPIONPLATFORM trial ( placebo control) was stopped early because an interim analysis showed disappointing results. The CHAMPION-PCI trial (clopidogrel as a comparator) failed to show a significant benefit as well. The most recent and largest study, the CHAMPION-PHOENIX trial, compared cangrelor against preloading with 300$600 \mathrm{mg}$ of clopidogrel. This study not only included ACS but also patients with stable CAD. It found a reduced risk for ischaemic events (death, MI, ischaemia-driven revascularisation or stent thrombosis) over the first $48 \mathrm{~h}$ without any increase in major bleeding risk..$^{49}$ Its role in clinical practice in the context of having ticagrelor and prasugrel available is not clear yet, and it has never been compared against these agents.

With additional and more potent antiplatelet therapies now available, the challenge is to decide which agent to use and when. Currently, the decision is usually based on clinical and risk factors; pharmacogenetics may also play a role in guiding therapies in the future. ${ }^{50}$

Gastrointestinal (GI) bleeding is one of the more common risks of strong antiplatelet therapy. Therefore, PPI are often prescribed as well. A recent study found, interestingly, that lower $\mathrm{Gl}$ bleeding is more common than upper GI bleeding in patients on PPI. ${ }^{51}$ Furthermore, the impact of PPI on the clopidogrel effect has been a matter of controversy for some time. Laboratory studies have suggested a reduced antiplatelet effect if PPI are used. However, studies looking at clinical end points have shown conflicting results. A recent systematic review provides a very good overview, including 33 studies, and concludes that clinical data are highly conflicting but that even newer, better designed studies do not show evidence of a relevant adverse effect of PPI in patients on clopidogrel regarding clinical outcomes. ${ }^{52}$

\section{Sudden Cardiac Arrest}

SCA is a less common but often fatal presentation of ACS ${ }^{53}$ While there are other reasons for SCA, especially in younger patients, the most common cause for tachyarrhythmic cardiac arrests in patients over 40 is myocardial ischaemia. ${ }^{47}$ Most of these cardiac arrests occur out of hospital (out-of-hospital cardiac arrest (OHCA)). Survival for OHCA patients has been poor for several decades, averaging $<10 \%$ to hospital discharge, and may be even lower, particularly in remote areas. However, in recent years survival has increased, especially in metropolitan areas. The London Ambulance Service observed an increase in survival rates from $12 \%$ to $32 \%$ between 2007 and $2012 .{ }^{5}$

We can only speculate about the reasons for this improvement since few single interventions have really proven to be effective. ${ }^{54}$ It is therefore more likely that it is the combination of multiple effective treatments that is responsible for the observed improvements in survival. Early chest compressions and early defibrillation are the undisputed game changers..$^{55}$ It is likely that the availability of public automatic defibrillators, defibrillators of the EMS and public awareness, and an increasing number of lay people trained in chest compression, played major roles..$^{56}$

However, other factors such as therapeutic hypothermia and immediate angiography to define and potentially treat the underlying cause are important as well. ${ }^{5758} \mathrm{An}$ observational study of 9971 patients with OHCA of suspected cardiac cause were assessed regarding the hospital they were referred to. Those treated at hospitals with $24 \mathrm{~h}$ cardiac interventional services had a better survival (OR 1.40, 95\% $\mathrm{Cl} 1.12$ to $1.74 ; \mathrm{p}=0.003$ ).

Current guidelines recommend immediate angiography in patients after successful resuscitation for an OHCA (return of a spontaneous circulation) in case of ST elevations in the postresuscitation ECG. However, the accuracy of post-resuscitation ECGs is unclear and there are grounds for recommending early angiography in all patients over $35-40$ years, regardless of the ECG, if there is no obvious non-cardiac cause.

\section{Cardiac rehabilitation after ACS}

While it seems intuitive that cardiac rehabilitation programmes are beneficial by providing careful follow-up, supervised physical activity and guidance on lifestyle modification, clinical data on its effect are controversial. Very recently, cardiac rehabilitation for ACS has been challenged again by the multicentre RCT of comprehensive cardiac rehabilitation in patients following acute $\mathrm{MI}$ (RAMIT: Rehabilitation After Myocardial Infarction Trial). ${ }^{59}$ In this study, cardiac rehabilitation in patients after an AMI had no effect on mortality or morbidity, cardiac medication, risk factors or lifestyle modification. However, we have to be aware that the RAMIT trial was small and if we look at the evidence more comprehensively, by pooling all available RCTs as done by a Cochrane review (combining 47 studies), there is a significant, albeit modest, effect on mortality. ${ }^{60}$ This meta-analysis did not include the RAMIT findings which would have further reduced the estimated effect on all cause mortality from $13 \%$ to $11 \% .{ }^{61}$ It is important to note that the Cochrane review focused on physical exercise based rehabilitation, the probability being that non-exercise based rehabilitation ( patient education) has little effect on mortality after $\mathrm{MI}^{62}$ 
The problem with combining results of multiple trials is, of course, that this does not account for the 'evolution' of such interventions. ${ }^{63}$ The results of the recent OMEGA study, which was a non-randomised cohort study, have shown that a short term comprehensive cardiac rehabilitation programme after acute MI significantly improved the 1-year prognosis. ${ }^{64}$ Those who attended rehabilitation programmes had lower all-cause mortality than those who did not, but without randomised treatment assignment, interpretation of such data is difficult. There was a significant dose-response relationship; the more sessions attended the lower the all-cause mortality. However, low attenders were more likely to be smokers, and when adjustmentswere made for baseline differences in smoking status the dose- response association disappeared.

Though cardiac rehabilitation as currently provided in many countries may not be effective in reducing hard clinical end points, it still helps provide information, advice, and reassurance and helps in long term secondary prevention. ${ }^{65}$

\section{Conclusions}

The treatment options for ACS have improved significantly over the past few years, contributing to notable improvements in outcomes. This is especially the case for STEMI, while long term mortality after an NSTE-ACS is still considerable. The very recent introduction of third generation antiplatelet therapies ( prasugrel, ticagrelor) and the most recent intravenous form, cangrelor, are likely to continue to improve clinical outcomes after ACS. These more potent agents can increase bleeding risks, and considering the association between bleeding and outcomes, periprocedural bleeding avoidance strategies are important. They may include radial access angiography, ultrasound guided femoral access, and the use of bivalirudin.

\section{References}

1 Members WG, Roger VL, Go AS, et al. Heart disease and stroke statistics - 2012 update: a report from the American Heart Association. Circulation 2012;125: e2-220.

2 Knight CJ, Timmis AD. Almanac 2011: acute coronary syndromes. The national society journals present selected research that has driven recent advances in clinical cardiology. Heart 2011;97:1820-7.

3 Yeh RW, Sidney S, Chandra M, et al. Population trends in the incidence and outcomes of acute myocardial infarction. N Engl J Med 2010;362:2155-65.

4 Nolan JP, Lyon RM, Sasson C, et al. Advances in the hospital management of patients following an out of hospital cardiac arrest. Heart 2012;98:1201-6.

5 Fothergill RT, Watson LR, Chamberlain D, et al. Increases in survival from out-of-hospital cardiac arrest: a five year study. Resuscitation 2013;84:1089-92.

6 Stone GW, Maehara A, Witzenbichler B, et al. Intracoronary abciximab and aspiration thrombectomy in patients with large anterior myocardial infarction: the INFUSE-AMI randomized trial. JAMA 2012;307:1817-26.

7 Stone GW, Witzenbichler B, Guagliumi G, et al. Heparin plus a glycoprotein IIb/IIla inhibitor versus bivalirudin monotherapy and paclitaxel-eluting stents versus bare-metal stents in acute myocardial infarction (HORIZONS-AMI): final 3-year results from a multicentre, randomised controlled trial. Lancet 2011;377:2193-204.

8 Kimmelstiel C, Zhang P, Kapur NK, et al. Bivalirudin is a dual inhibitor of thrombin and collagen-dependent platelet activation in patients undergoing percutaneous coronary intervention. Circ Cardiovasc Interv 2011;4:171-9.
9 Meier P, Frohlich GM, Lansky AJ. Bleeding complications in percutaneous coronary interventions. Cardiology 2013;125:213-16.

10 Mamas MA, Ratib K, Routledge $\mathrm{H}$, et al. Influence of access site selection on PCl-related adverse events in patients with STEMI: metaanalysis of randomised controlled trials. Heart 2012;98:303-11.

11 Meier P, Windecker S, Lansky AJ. Radial versus femoral access for primary percutaneous coronary intervention: is there a preferred route to the heart? Heart 2012;98:269-70.

12 Baklanov DV, Kaltenbach LA, Marso SP, et al. The prevalence and outcomes of transradial percutaneous coronary intervention for ST-segment elevation myocardial infarction: analysis from the National Cardiovascular Data Registry (2007 to 2011). J Am Coll Cardiol 2013;61:420-6.

13 Cafri C, Zahger D, Merkin M, et al. Efficacy of the radial approach for the performance of primary PCI for STEMI. J Invasive Cardiol 2013;25:150-3.

14 Secco GG, Marinucci L, Uguccioni L, et al. Transradial versus transfemoral approach for primary percutaneous coronary interventions in elderly patients. J Invasive Cardiol 2013;25:254-6.

15 Ratib K, Mamas MA, Routledge HC, et al. Influence of access site choice on incidence of neurologic complications after percutaneous coronary intervention. Am Heart J 2013;165:317-24.

16 Ratib K, Routledge H, Mamas MA, et al. Trends in access site choice and $\mathrm{PCl}$ outcomes: insights from the UK national $\mathrm{PCl}$ dataset. Heart 2012;98:A28-A9.

17 Feldman DN, Swaminathan RV, Kaltenbach LA, et al. Adoption of radial access and comparison of outcomes to femoral access in percutaneous coronary intervention: an updated report from the National Cardiovascular Data Registry (2007-2012). Circulation 2013;127:2295-306.

18 De Luca G, Schaffer A, Wirianta J, et al. Comprehensive metaanalysis of radial vs femoral approach in primary angioplasty for STEMI. Int J Cardiol 2013 (Epub ahead of print).

19 Mehta SR, Jolly SS, Cairns J, et al. Effects of radial versus femoral artery access in patients with acute coronary syndromes with or without ST-segment elevation. J Am Coll Cardiol 2012;60:2490-9.

20 Klutstein MW, Westerhout CM, Armstrong PW, et al. Radial versus femoral access, bleeding and ischemic events in patients with non-ST-segment elevation acute coronary syndrome managed with an invasive strategy. Am Heart J 2013;165:583-90 e1.

21 Hamon M, Pristipino C, Di Mario C, et al. Consensus document on the radial approach in percutaneous cardiovascular interventions: position paper by the European Association of Percutaneous Cardiovascular Interventions and Working Groups on Acute Cardiac Care and Thrombosis of the European Society of Cardiology. Eurolntervention 2013;8:1242-51.

22 Politi L, Sgura F, Rossi R, et al. A randomised trial of target-vessel versus multi-vessel revascularisation in ST-elevation myocardial infarction: major adverse cardiac events during long-term follow-up. Heart 2010;96:662-7.

23 Abe D, Sato A, Hoshi T, et al. Initial culprit-only versus initial multivessel percutaneous coronary intervention in patients with ST-segment elevation myocardial infarction: results from the Ibaraki Cardiovascular Assessment Study registry. Heart Vessels 2013 March 26th (Epub ahead of print).

24 Brener SJ, Milford-Beland S, Roe MT, et al. Culprit-only or multivessel revascularization in patients with acute coronary syndromes: an American College of Cardiology National Cardiovascular Database Registry report. Am Heart J 2008;155:140-6.

25 Vlaar PJ, Mahmoud KD, Holmes DR Jr, et al. Culprit vessel only versus multivessel and staged percutaneous coronary intervention for multivessel disease in patients presenting with ST-segment elevation myocardial infarction: a pairwise and network meta-analysis. J Am Coll Cardiol 2011;58:692-703.

26 Wijns W, Kolh P, Danchin N, et al. Guidelines on myocardial revascularization. Eur Heart J 2010;31:2501-55.

27 Kushner FG, Hand M, Smith SC Jr, et al. 2009 focused updates: ACC/AHA guidelines for the management of patients with STelevation myocardial infarction (updating the 2004 guideline and 2007 focused update) and ACC/AHA/SCAI guidelines on percutaneous coronary intervention (updating the 2005 guideline and 2007 focused update): a report of the American College of Cardiology Foundation/ American Heart Association Task Force on Practice Guidelines. J Am Coll Cardiol 2009;54:2205-41. 
28 Wijns W, Kolh P, Danchin N, et al. Guidelines on myocardial revascularization: the Task Force on Myocardial Revascularization of the European Society of Cardiology (ESC) and the European Association for Cardio-Thoracic Surgery (EACTS). Eur Heart J 2010;31:2501-55.

29 Eagle KA, Nallamothu BK, Mehta RH, et al. Trends in acute reperfusion therapy for ST-segment elevation myocardial infarction from 1999 to 2006: we are getting better but we have got a long way to go. Eur Heart J 2008;29:609-17.

30 Terkelsen CJ, Sorensen JT, Maeng M, et al. System delay and mortality among patients with STEMI treated with primary percutaneous coronary intervention. JAMA 2010;304:763-71.

31 Rollando D, Puggioni E, Robotti S, et al. Symptom onset-to-balloon time and mortality in the first seven years after STEMI treated with primary percutaneous coronary intervention. Heart 2012;98:1738-42.

32 Khavandi A, Freeman P, Meier P. Discharge after primary angioplasty at $24 \mathrm{~h}$ : feasible and safe or a step too far? Cardiology 2013;125:176-9.

33 Schmidt M, Jacobsen JB, Lash TL, et al. 25 year trends in first time hospitalisation for acute myocardial infarction, subsequent short and long term mortality, and the prognostic impact of sex and comorbidity: a Danish nationwide cohort study. BMJ 2012;344:e356.

34 Jones DA, Rathod KS, Howard JP, et al. Safety and feasibility of hospital discharge 2 days following primary percutaneous intervention for ST-segment elevation myocardial infarction. Heart 2012;98:1722-7.

35 Noman A, Zaman AG, Schechter C, et al. Early discharge after primary percutaneous coronary intervention for ST-elevation myocardial infarction. Eur Heart J Acute Cardiovasc Care 2013 February 14th (epub ahead of print).

36 Simms AD, Reynolds S, Pieper K, et al. Evaluation of the NICE mini-GRACE risk scores for acute myocardial infarction using the Myocardial Ischaemia National Audit Project (MINAP) 20032009: National Institute for Cardiovascular Outcomes Research (NICOR). Heart 2012;99:35-40.

37 Jolly SS, Shenkman H, Brieger D, et al. Quantitative troponin and death, cardiogenic shock, cardiac arrest and new heart failure in patients with non-ST-segment elevation acute coronary syndromes (NSTE ACS): insights from the Global Registry of Acute Coronary Events. Heart 2011;97:197-202.

38 Oemrawsingh RM, Lenderink T, Akkerhuis KM, et al. Multimarker risk model containing troponin-T, interleukin 10, myeloperoxidase and placental growth factor predicts long-term cardiovascular risk after non-ST-segment elevation acute coronary syndrome. Heart 2011;97:1061-6.

39 Stone GW, Maehara A, Lansky AJ, et al. A prospective naturalhistory study of coronary atherosclerosis. N Engl J Med 2011;364:226-35.

40 Lodi-Junqueira L, de Sousa MR, da Paixao LC, et al. Does intravascular ultrasound provide clinical benefits for percutaneous coronary intervention with bare-metal stent implantation? A metaanalysis of randomized controlled trials. Syst Rev 2012;1:42.

41 Maehara A, Mintz GS, Weissman NJ. Advances in intravascular imaging. Circ Cardiovasc Interv 2009;2:482-90.

42 Yabushita H, Bouma BE, Houser SL, et al. Characterization of human atherosclerosis by optical coherence tomography. Circulation 2002;106:1640-5.

43 Kubo T, Imanishi T, Takarada S, et al. Assessment of culprit lesion morphology in acute myocardial infarction: ability of optical coherence tomography compared with intravascular ultrasound and coronary angioscopy. J Am Coll Cardiol 2007;50:933-9.

44 Lindsay AC, Viceconte N, Di Mario C. Optical coherence tomography: has its time come? Heart 2011;97:1361-2.

45 Alfonso F, Dutary J, Paulo M, et al. Combined use of optical coherence tomography and intravascular ultrasound imaging in patients undergoing coronary interventions for stent thrombosis. Heart 2012;98:1213-20.
46 Sambu N, Radhakrishnan A, Dent H, et al. Personalised antiplatelet therapy in stent thrombosis: observations from the Clopidogrel Resistance in Stent Thrombosis (CREST) registry. Heart 2012;98:706-11.

47 Park KW, Park JJ, Lee SP, et al. Cilostazol attenuates on-treatment platelet reactivity in patients with CYP2C19 loss of function alleles receiving dual antiplatelet therapy: a genetic substudy of the CILON-T randomised controlled trial. Heart 2012;97:641-7.

48 Tamhane U, Meier P, Chetcuti S, et al. Efficacy of cilostazol in reducing restenosis in patients undergoing contemporary stent based PCl: a meta-analysis of randomised controlled trials. Eurolntervention 2009;5:384-93.

49 Bhatt DL, Stone GW, Mahaffey KW, et al. Effect of platelet inhibition with cangrelor during $\mathrm{PCl}$ on ischemic events. N Engl J Med 2013;368:1303-13.

50 Verschuren JJ, Jukema JW. Pharmacogenetics of antiplatelet therapy: ready for clinical application? Heart 2011;97:1268-76.

51 Casado Arroyo R, Polo-Tomas M, Roncales MP, et al. Lower GI bleeding is more common than upper among patients on dual antiplatelet therapy: long-term follow-up of a cohort of patients commonly using PPI co-therapy. Heart 2012;98:718-23.

52 Focks JJ, Brouwer MA, van Oijen MG, et al. Concomitant use of clopidogrel and proton pump inhibitors: impact on platelet function and clinical outcomea systematic review. Heart 2013;99:520-7.

53 Perkins GD, Brace SJ, Smythe M, et al. Out-of-hospital cardiac arrest: recent advances in resuscitation and effects on outcome. Heart 2011;98:529-35.

54 Brooks SC, Bigham BL, Morrison LJ. Mechanical versus manual chest compressions for cardiac arrest. Cochrane Database Syst Rev 2011:CD007260, doi.10.1002/ 14651858.CD007260.pub2.

55 Meier $P$, Baker $P$, Jost $D$, et al. Chest compressions before defibrillation for out-of-hospital cardiac arrest: a meta-analysis of randomized controlled clinical trials. BMC Med 2010;8:52.

56 Adielsson A, Hollenberg J, Karlsson T, et al. Increase in survival and bystander CPR in out-of-hospital shockable arrhythmia: bystander CPR and female gender are predictors of improved outcome. Experiences from Sweden in an 18-year perspective. Heart 2011;97:1391-6.

57 Arrich J, Holzer M, Havel C, et al. Hypothermia for neuroprotection in adults after cardiopulmonary resuscitation. Cochrane Database Syst Rev 2012;(9): CD004128.

58 Stub D, Smith K, Bray JE, et al. Hospital characteristics are associated with patient outcomes following out-of-hospital cardiac arrest. Heart 2011;97:1489-94.

59 West RR, Jones DA, Henderson AH. Rehabilitation after myocardial infarction trial (RAMIT): multi-centre randomised controlled trial of comprehensive cardiac rehabilitation in patients following acute myocardial infarction. Heart 2012;98:637-44.

60 Heran BS, Chen JM, Ebrahim S, et al. Exercise-based cardiac rehabilitation for coronary heart disease. Cochrane Database Syst Rev 2011:CD001800, doi.10.1002/ 14651858.CD001800.pub2.

61 Doherty P, Lewin R. The RAMIT trial, a pragmatic RCT of cardiac rehabilitation versus usual care: what does it tell us? Heart 2012;98:605-6.

62 Brown JP, Clark AM, Dalal H, et al. Patient education in the management of coronary heart disease. Cochrane Database Syst Rev 2011:CD008895.

63 Wood D. Is cardiac rehabilitation fit for purpose in the NHS: maybe not. Heart 2012;98:607-8.

64 Rauch B, Riemer T, Schwaab B, et al. Short-term comprehensive cardiac rehabilitation after $\mathrm{AMI}$ is associated with reduced 1-year mortality: results from the OMEGA study. Eur J Prev Cardiol 2013 doi: 10.1002/14651858.CD008895. pub2.

65 West RR, Henderson AH. Cardiac rehabilitation and exercise training. Heart 2013;99:753-4. 